\title{
Long-term influence of sialoadenectomy on reproductive performance of male mice
}

\author{
A. B. V. Reyes and N. Wakasugi* \\ Laboratory of Animal Reproduction, School of Agricultural Sciences, Nagoya University, Furo-cho, \\ Chikusa-ku, Nagoya, 464, Japan
}

\begin{abstract}
The influence of the submandibular gland, the major source of epithelial growth factor, on male reproduction in mice was studied by removing the submandibular gland (sialoadenectomy) and examining its effects on sperm production and copulation and fertility rates over an extended post-operation period. The removal of the submandibular gland caused a decrease in the number of epididymal spermatozoa 4 weeks after the operation; the decrease became significant $(P<0.05)$ 6-10 weeks after the operation compared with the sham operated and intact groups. There was no significant difference between prepuberal ( 30 days oid) and postpuberal ( 60 days old) sialoadenectomy, indicating that the submandibular gland is not related to the maturation of the seminiferous tubules. The reduction in the number of epididymal spermatozoa was due to the decrease in number of spermatogonia and spermatocytes per Sertoli cell in the seminiferous tubules. When the reproductive performance was examined over 14 weeks, sialoadenectomized males showed a lower copulation rate and a significantly $(P<0.05)$ higher incidence of non-fertile copulation compared with the sham-operated and intact males. These results indicate that the submandibular gland and the secretion of epithelial growth factor from it affect spermatogenesis by acting on spermatogonial proliferation and sperm maturation.
\end{abstract}

\section{Introduction}

Epithelial growth factor (EGF) receptors have been shown to be present in the Leydig cells and Sertoli cells of adult mouse testes (Suarez-Quian and Niklinski, 1990; Suarez-Quian et al., 1994), in the epididymis and vas deferens of non-human primates (Radhakrishnan and Suarez-Quian, 1992), as well as in the prostate glands of rats (Traish and Wotiz, 1987), indicating that EGF has some effects on male reproduction. EGF has been shown to interact with testosterone in the differentiation and development of the Wolffian duct (Gupta et al., 1991; Gupta and Jaumotte, 1993), and to participate in the regulation of androgen synthesis (Verhoeven and Cailleau, 1986; Sordoillet et al., 1991) and stimulation of sperm capacitation (Furuya $e t$ al., 1993). In mice, the submandibular gland is the major source of EGF (Barka, 1980) and the EGF content of the gland gradually increases from $0.02 \mathrm{ng} \mathrm{mg}^{-1}$ wet tissue at 15 days of age to $0.30 \mathrm{ng} \mathrm{mg}^{-1}$ at 20 days, $47 \mathrm{ng} \mathrm{mg}^{-1}$ at 29 days, reaching a maximum of about $1000 \mathrm{ng} \mathrm{mg}^{-1}$ at 50 days (Byyny et al., 1972). This increase in the EGF content of the submandibular gland is related to sexual maturation and has been shown to be androgen dependent (Byyny et al., 1974).

The removal of submandibular gland (sialoadenectomy) results in a reduction in the number of epididymal spermatozoa (Tsutsumi et al., 1986; Russell et al., 1990). On the basis of these and other findings, the existence of a submandibular gland-

${ }^{*}$ Correspondence and reprint requests.

Received 11 April 1995. gonadal axis that controls spermatogenesis has been suggested by Tsutsumi et al. (1986) and Noguchi et al. (1990). However, Tokida et al. (1988) found no significant difference in fertility rate between sialoadenectomized and sham-operated male mice, and concluded that the submandibular gland has no role in reproductive function in male mice.

The present report provides additional evidence showing that the submandibular gland is related to the spermatogenic activity in mice. The reduction in both the number of epididymal spermatozoa and fertility in sialoadenectomized male mice could be significant if observation is made over an extended period of time.

\section{Materials and Methods}

\section{Animals and treatments}

ICR mice (ICR:slc) purchased from Shizuoka Laboratory Animal Corporation, Shizuoka, Japan and their descendants were used for the present study. They were kept under controlled conditions $\left(22 \pm 2^{\circ} \mathrm{C}\right.$ and under a photoperiod of $14 \mathrm{~h}$ light: $10 \mathrm{~h}$ dark) and given the commercial pellet diet (CA-I: Clea Japan Inc., Tokyo) and water ad libitum.

Ninety males, aged 30 days, were randomly placed into one of three groups, sialoadenectomized, sham-operated or intact groups. Sialoadenectomy or the sham operation were carried out at 30 days of age (prepuberal sialoadenectomy). After the experimental animals were anaesthetized with diethyl ether 
(Yoneyama Yakuhin Company, Osaka), an incision was made in the ventral portion of the cervical region to open the skin. For the sialoadenectomized group, the submandibular glands were removed after ligating two parallel vessels entering the glands, the glandular branches of the external maxillary artery and anterior facial vein, while for the sham-operated group, the submandibular glands were manipulated without removing them. Six mice from each group, of approximately the same body mass, were used for the sperm count and histological examination of testes $2,4,6,8$ and 10 weeks after the operation. Another set of 18 males underwent sialoadenectomy at the age of 60 days and groups of six males were killed by cervical dislocation at the age of 75,90 and 105 days to compare the effects of prepuberal and postpuberal sialoadenectomy.

\section{Number of spermatozoa}

The number of spermatozoa in the epididymides was determined according to the method of Taylor et al. (1985). The epididymides were removed, weighed, finely minced and placed in $2 \mathrm{ml}$ of $0.9 \%(\mathrm{w} / \mathrm{v}) \mathrm{NaCl}$. The number of spermatozoa in seven chambers of a haemocytometer were counted; the highest and lowest scores were discounted and the number of spermatozoa was calculated from the counts in the five chambers. Two counts were made for each epididymis. The number of epididymal spermatozoa of a male was expressed as the mean of the counts from left and right epididymides.

\section{Examination of the seminiferous tubules under the microscope}

The left and right testes were weighed and fixed overnight in Bouin's solution. Fixed tissues were embedded in paraffin wax, sectioned at $6 \mu \mathrm{m}$ and stained with haematoxylin and eosin. The spermatogenic activity was estimated as the 'Sertoli Cell Ratio' as described by Gosden et al. (1982). For each male, 20 seminiferous tubules at stages II-VI with approximately circular cross-section were randomly selected. The number of spermatogonia, spermatocytes and early spermatids in those tubules was counted under oil immersion $(x 1000)$ and expressed as a ratio to the number of Sertoli cells in the same tubule.

The diameter of the seminiferous tubule was represented by the shorter diameter of the tubules ( 20 tubules per animal) used to count the germinal cells. The tubular lumen was measured for the stage VII seminiferous tubule (20 tubules per animal).

\section{Fertility of sialoadenectomized and sham-operated mice}

A fertility test was carried out on mice that underwent sialoadenectomy or the sham-operation at 30 days of age, one month after the operation. Female mice were caged individually with the males between $14: 00$ and $15: 00 \mathrm{~h}$ on day 1 . Females were examined for the presence of a vaginal plug every morning until day 6 . Females with a vaginal plug were kept separately until parturition. Pregnancy was confirmed either by a vaginal haemorrhage 11-12 days after copulation or by an increase in body mass. Females with no vaginal plug were caged individually for 2 weeks and, after being confirmed as not pregnant, they were used for the next experiment. Males underwent the fertility test for 14 consecutive weeks.

\section{Statistical analyses}

Comparison of the Sertoli cell ratio between groups was carried out by the Wilcoxon's test as described by Gosden et al. (1982) and other group comparisons were made by analysis of variance or Student's $t$ test. Mean comparison was made by Duncan's Multiple Range Test. The linear relationship between body mass and number of spermatozoa was determined by correlation and regression analysis.

\section{Results}

The removal of the submandibular gland at 30 days of age resulted in a lower body mass (Fig. 1) and a significant difference $(P<0.01)$ was noted between the sialoadenectomized and intact groups 6 weeks after the operation and between the sialoadenectomized group and both control groups (sham-operated and intact) $(P<0.05)$ at 10 weeks. The sham-operated mice consistently had a lower body mass than did the intact mice but the difference was not significant $(P>0.05)$. It is interesting that the sialoadenectomized mice had lower body mass as their feed intake was higher than the other groups. When measured up to 9 weeks after the operation, sialoadenectomized mice $(n=4)$ had a mean feed intake of $47.8 \mathrm{~g}$ per week while the sham-operated mice $(n=5)$ had an intake of $41.2 \mathrm{~g}$ per week.

The number of epididymal spermatozoa in prepuberal sialoadenectomized males was consistently lower than in the sham-operated and intact males at 2, 4, 6, 8, and 10 weeks after the operation (Fig. 2). With the exception of the second week,

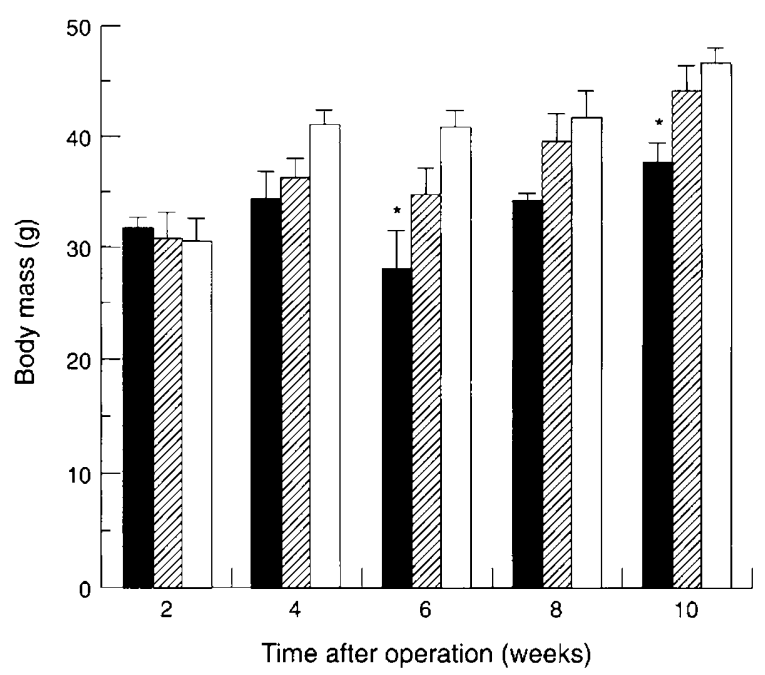

Fig. 1. Body mass of prepuberal ( 30 days of age) sialoadenectomized $(\square)$, sham-operated $(\square)$ and intact $(\square)$ ICR male mice. Results are expressed as means $\pm \operatorname{SEM}(n=6)$. *Significantly different from the intact group $(P<0.01)$ at 6 weeks and from the sham-operated and intact groups $(P<0.05)$ at 10 weeks after the operation. No significant $(P>0.05)$ difference was seen between the sham-operated and intact groups throughout the post-operation period. 


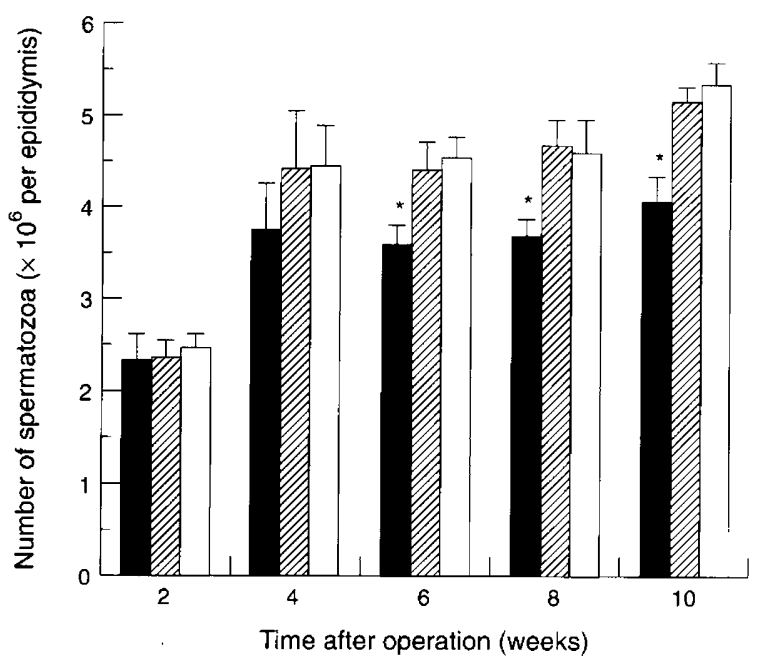

Fig. 2. Number of epididymal spermatozoa in prepuberal ( 30 days of age) sialoadenectomized ( $\mathbf{\square})$, sham-operated $(\square)$ and intact $(\square)$ ICR male mice. Results are expressed as means \pm SEM. ${ }^{*}$ Significantly different from the sham-operated and intact groups $(P<0.05)$.

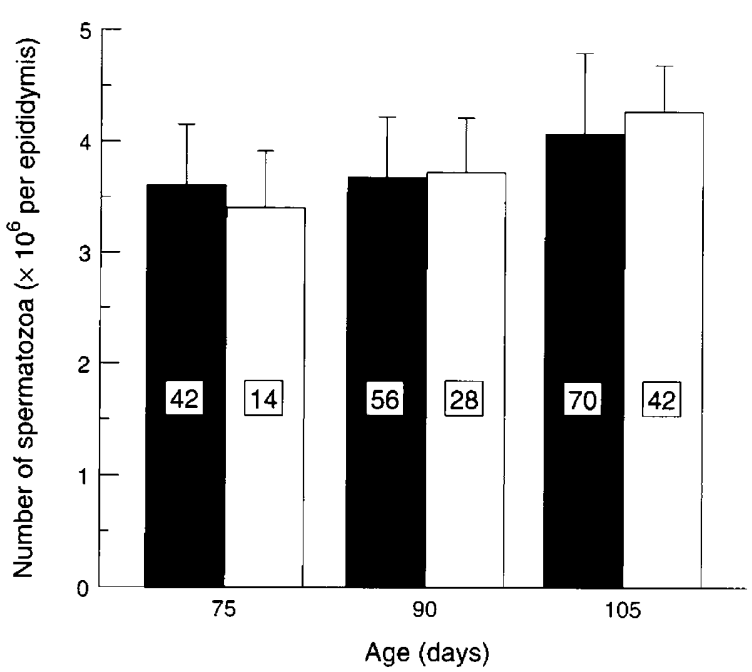

Fig. 3. Comparison of number of epididymal spermatozoa between

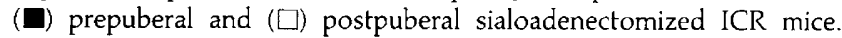
No significant difference $(P>0.05)$ was noted at any stage between the two groups. Figures within bars are the times (days) after sialoadenectomy.

the difference was approximately $20 \%$ and the difference was significant $(P<0.05)$ after 6 weeks. A comparison of the effect of prepuberal (at 30 days) and postpuberal (at 60 days) sialoadenectomy on number of spermatozoa showed no significant difference (Fig. 3). The sperm count was carried out at 75,90 and 105 days of age, regardless of the time of sialoadenectomy; therefore, the prepuberal data correspond to the measurements at 6,8 and 10 weeks after the operation (as shown in Fig. 2).

A correlation analysis was made between body mass and epididymal sperm count 10 weeks after the operation to determine whether the difference in body mass had an influence on the epididymal sperm count. There was no significant
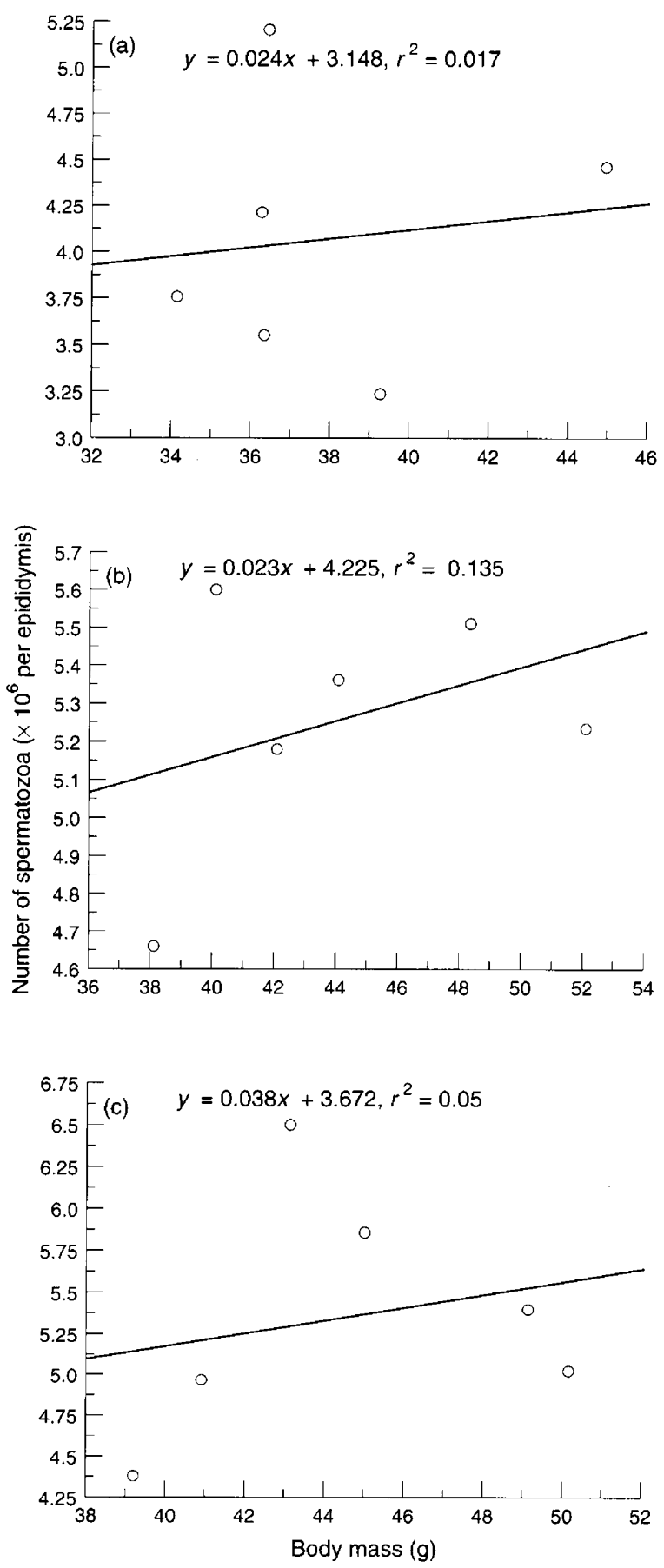

Fig. 4. Correlation between body mass and number of spermatozoa in (a) sialoadenectomized, (b) sham-operated and (c) intact ICR male mice 10 weeks after sialoadenectomy. Correlation coefficient values in the three groups, (a) $r=0.167$, (b) $r=0.012$ and (c) $r=0.168$ were not significant $(P>0.05)$.

correlation between the two variables in any of the males in the three experimental groups (Fig. 4).

Representative histological micrographs of the seminiferous tubules from sialoadenectomized and sham-operated mice and each representative cell type counted in the present study are shown (Fig. 5). 

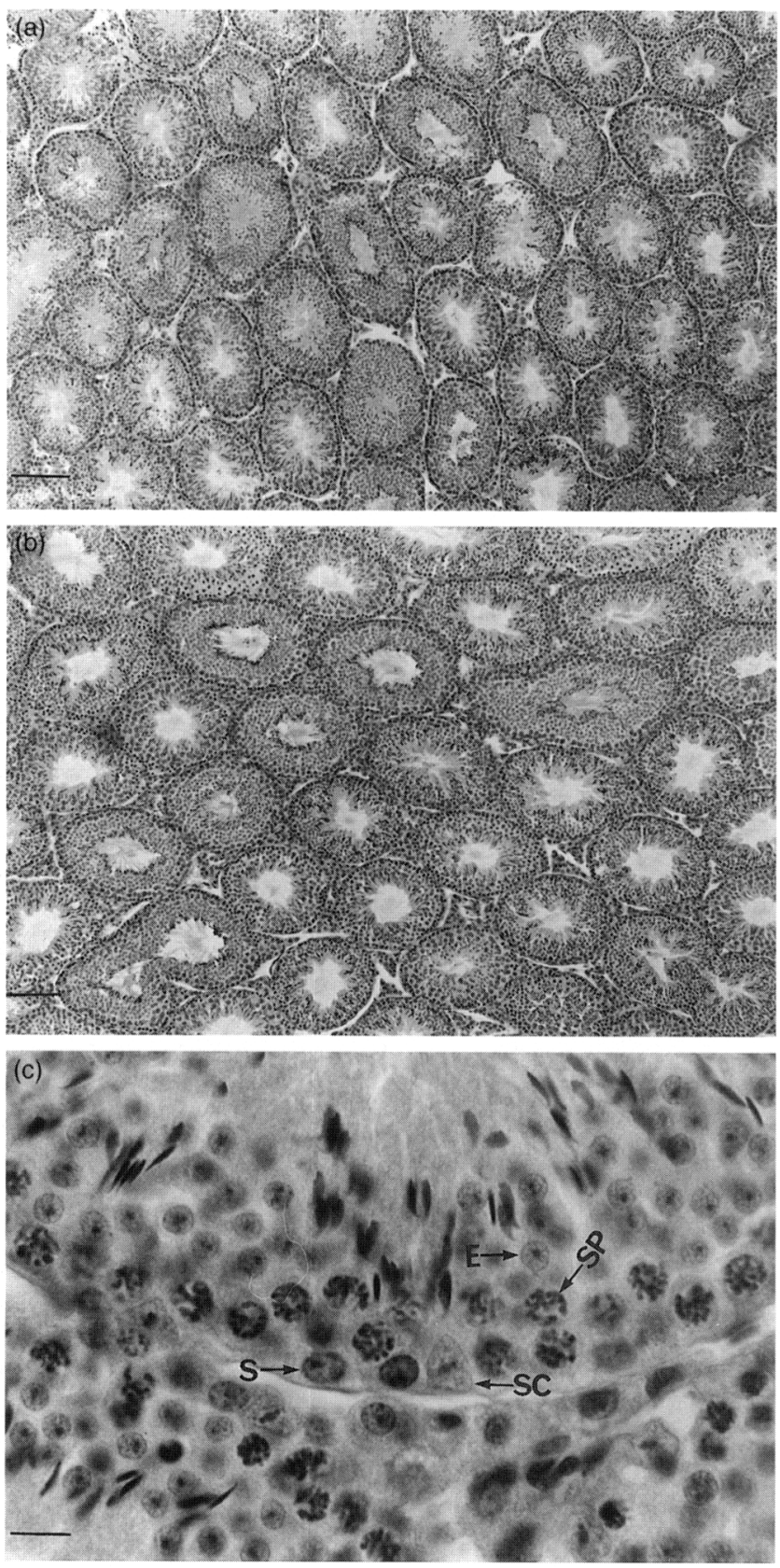

Fig. 5. Micrographs of the seminiferous tubules from (a) a sialoadenectomized and (b) a sham-operated ICR mouse. (c) The seminiferous tubules of a sialoadenectomized mouse, in which each representative cell type is indicated; S: spermatogonia; SP: spermatocytes; E: early spermatids and SC: Sertoli cells. Scale bars represent (a and b) $100 \mu \mathrm{m}$ and (c) $10 \mu \mathrm{m}$.

Histological observation revealed that the significant reduction in the number of epididymal spermatozoa in sialoadenectomized males at 8 weeks was due to the lower number of spermatogonial cells per Sertoli cell in the seminiferous tubules (Table 1). This reduced number of spermatogonial cells is thought to result in the reduction in the number of spermatocytes and early spermatids. This reduction in the number of germinal cells per Sertoli cell in the sialoadenectomized mice was accompanied by a significant reduction in the size of the seminiferous tubules, but there was no apparent effect on the size of the tubular lumen (Table 2). The number of Sertoli cells was not affected by the removal of the submandibular gland.

The reproductive performance of the three groups of males, mated with a female once a week for 14 consecutive weeks is shown (Table 3). A decrease in the reproductive performance of sialoadenectomized mice was observed; the numbers of copulations and pregnancies were lower when compared with results from sham-operated and intact males. Furthermore, a significant $(P<0.05)$ difference was noted in the pregnancy rate between the sialoadenectomized and intact groups. These findings are consistent with the reduction in the Sertoli cell ratio of germinal cells in the sialoadenectomized males. Litter size was similar in all three groups. When analysed on a per month basis, all the three groups showed a progressive reduction in the total pregnancy rate but the lowest rate was consistently observed in the sialoadenectomized group (Fig. 6).

\section{Discussion}

A reduction in the number of epididymal spermatozoa after the removal of the submandibular gland has previously been reported in mice. Tsutsumi et al. (1986) observed a 40-50\% reduction while Russell et al. (1990) noted only a $10 \%$ reduction in the number of spermatozoa. In these experiments, sialoadenectomy was carried out at 14 weeks of age, and the number of epididymal spermatozoa was counted 4 weeks after the operation. In the present study, sialoadenectomy was performed at 30 days of age when salivary EGF content is low: approximately $47 \mathrm{ng} \mathrm{mg}^{-1}$, well below the maximum of about $1000 \mathrm{ng} \mathrm{mg}^{-1}$ observed in mature male mice (Byyny et al., 1972). This prepuberal sialoadenectomy resulted in about a $20 \%$ reduction in the number of epididymal spermatozoa 4 weeks after the operation and the reduction was significant $(P<0.05) 6-10$ weeks after the operation. However, there were no significant differences in the number of epididymal spermatozoa between prepuberal and postpuberal sialoadenectomized mice at 75,90 and 105 days of age. This finding and the presence of normal seminiferous epithelium at 45 days of age after prepuberal sialoadenectomy at 30 days indicate that the submandibular gland has no apparent contribution to the maturation of seminiferous tubules, despite the increase in EGF synthesis in the submandibular gland resulting from increasing androgen production during this period.

Peerheentupa et al. (1984) reported a lower body mass among sialoadenectomized mice, indicating that the removal of the submandibular gland has a significant effect on growth. Similar growth suppression or retardation was seen in the present study. However, this inhibition of growth had no effects on the number of epididymal spermatozoa as shown by the absence of correlation between the two variables. It is interesting, however, that the sialoadenectomized mice had lower body mass despite a higher feed intake. One possible explanation of the growth inhibition is that there is a reduction in growth hormone secretion as a result of lower EGF concentrations (Ikeda et al., 1984).

Tsutsumi et al. (1986) reported that sialoadenectomy causes an increase in the number of primary spermatocytes and 
Table 1. Ratio of germ cells to Sertoli cells in sialoadenectomized, sham-operated and intact ICR male mice ${ }^{a}$

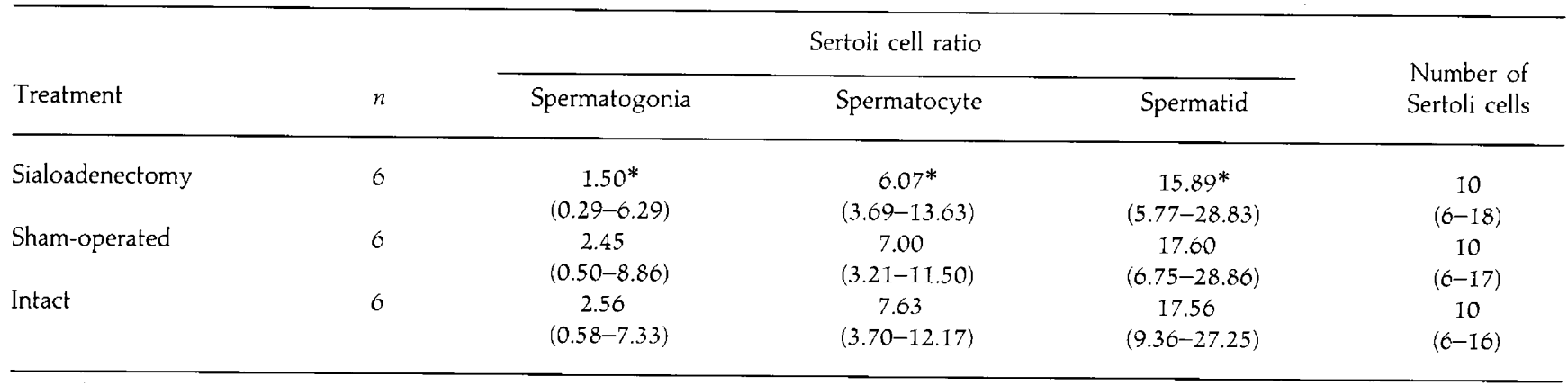

${ }^{2}$ Sialoadenectomy was carried out at 30 days of age and the cellular composition was examined at 86 days of age. The Sertoli cell ratio is shown as the ratio of number of germ cells to the number of Sertoli cells in the same seminiferous tubule segments and the values are shown as medians and ranges.

*These values are significantly different from those of the sham-operated and intact groups $(P<0.01$; Wilcoxon's test).

Table 2. Diameters $(\mu \mathrm{m})$ of the seminiferous tubules and tubular lumen in sialoadenectomized, sham-operated and intact ICR mice $^{a}$

\begin{tabular}{lccc}
\hline Treatment & $n$ & $\begin{array}{c}\text { Diameter of } \\
\text { seminiferous tubule }\end{array}$ & $\begin{array}{c}\text { Diameter of } \\
\text { tubule lumen }\end{array}$ \\
\hline Sialoadenectomy & 6 & $145.23 \pm 2.49^{*}$ & $45.94 \pm 1.38$ \\
Sham-operated & 6 & $150.64 \pm 2.09$ & $44.59 \pm 1.54$ \\
Intact & 6 & $149.32 \pm 2.65$ & $46.01 \pm 2.34$ \\
\hline
\end{tabular}

aData are presented as mean \pm SEM.

*Significantly $(P<0.05)$ different from the sham-operated and intact groups.

a reduction in the number of round spermatids, indicating a disturbance of the meiotic division in spermatogenesis. Suarez-Quian et al. (1994) however, suggested that the fall in plasma EGF concentrations after sialoadenectomy in adult male mice leads to a diminution in spermatogonial mitotic activity in the basal compartment of the seminiferous epithelium. This suggestion is supported by the finding in the present study that the number of spermatogonia per Sertoli cell was significantly lower in the sialoadenectomized mice compared with the sham-operated and intact mice. This is consistent with the finding of Bartlett et al. (1990) that the concentration of EGF in the stage-synchronized rat testes increases at stages IX-II of the seminiferous tubule cycle, corresponding to the mitotic division of type A spermatogonia at stages IX, XII and XIV. In addition, EGF induces differentiation of type A spermatogonia in vitro (Haneji et al., 1991). In the present study, the reduction in the number of epididymal spermatozoa due to prepuberal sialoadenectomy was observed 4 weeks after the operation. Since spermatogenesis in mice takes approximately a month for completion (Clermont and Trott, 1969), the reduced number of spermatozoa after sialoadenectomy is thought to be attributed to fewer spermatogonia undergoing differentiation into the spermatocyte stage approximately a month before. It is necessary to mention here that the use of the 'Sertoli cell ratio' as a method of quantifying the germinal cells in the present study is based on the fact that sialoadenectomy does not cause any reduction in the number of Sertoli cells per seminiferous tubule and hence the ratio can be used as an indicator of the spermatogenic activity of the testis (Skakkebaek and Heller, 1973).

The reduction in the number of germinal cells per Sertoli cell was accompanied by a significant reduction in the size of the seminiferous tubules. A similar reduction in the tubule diameter of mice has been observed when the number of spermatids was reduced (Tajima et al., 1991). However, no significant reduction in the lumen size was observed in the present study.

Sialoadenectomy resulted in not only a reduced copulation rate, but also a significant reduction in the pregnancy rate, that is, a higher incidence of non-fertile copulation. This higher incidence of non-fertile copulation could be attributed to the oligozoospermic condition resulting from EGF deficiency (Noguchi et al., 1990) or a reduction in secretion from seminal vesicle which would cause a fall in the number of spermatozoa transported to the uterus (Carbaliada and Esponda, 1992). The mass of the seminal vesicles of sialoadenectomized mice was lower than that of the sham-operated group (136 mg versus $211 \mathrm{mg}$ ) at 90 days. In a mating experiment with sialoadenectomized DDY males and normal females in which the cohabitation period was short (36-48 h), Tokida et al. (1988) found no significant reduction in the pregnancy rate. In the present study, reproductive function of the sialoadenectomized mice was examined for 14 consecutive weeks, and significant reduction in reproductive performance was observed. It is worth noting that the pregnancy rate for the three groups in the present study was similar for the first exposure to female mice, coincident with the finding of Tokida et al. (1988). As the mating experiment progressed, there was a general decrease in the pregnancy rate in all the three groups; however, the reduction was greatest in the sialoadenectomized group and this was particularly noticeable when the pregnancy rate was calculated for the entire experimental period. This accelerated and progressive reduction in reproductive performance may reflect a progressive decline in germinal epithelial activity, since a major role of EGF in adult mammals is thought to be the maintenance of epithelial surface function (Fisher and Lakshmanan, 1990).

The reduction in number of spermatozoa (about 10\%) observed by Russell et al. (1990) in C3H males 4 weeks after the operation was not significant. As mentioned earlier, Tokida et al. (1988) observed no significant difference in the 
Table 3. Reproductive performance of prepuberal sialoadenectomized, sham-operated and intact ICR male mice mated with an ICR female every week for 14 consecutive weeks

\begin{tabular}{|c|c|c|c|c|c|c|}
\hline Treatment & $n$ & $\begin{array}{l}\text { Number of matings } \\
\text { per male }\end{array}$ & $\begin{array}{l}\text { Total number } \\
\text { of matings }\end{array}$ & $\begin{array}{l}\text { Copulation } \\
\text { rate }(\%)\end{array}$ & $\begin{array}{l}\text { Pregnancy } \\
\text { rate }(\%)\end{array}$ & $\begin{array}{l}\text { Average } \\
\text { litter size }\end{array}$ \\
\hline Sialoadenectomy & 5 & 14 & 70 & $\begin{array}{c}32 / 70 \\
(45.71)\end{array}$ & $\begin{array}{l}24 / 32^{*} \\
(75.00)\end{array}$ & 11.84 \\
\hline Sham-operated & 5 & 14 & 70 & $\begin{array}{c}43 / 70 \\
(61.43)\end{array}$ & $\begin{array}{l}38 / 43 \\
(88.37)\end{array}$ & 12.00 \\
\hline Intact & 5 & 14 & 70 & $\begin{array}{c}41 / 70 \\
(58.57)\end{array}$ & $\begin{array}{l}40 / 41 \\
(97.57)\end{array}$ & 11.95 \\
\hline
\end{tabular}

*Significantly different from the intact group $(P<0.05)$.

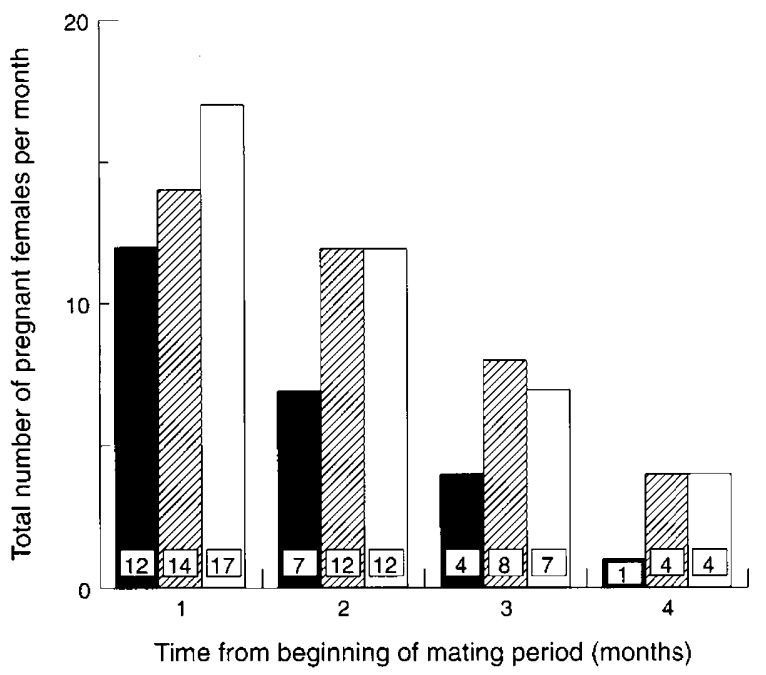

Fig. 6. Total number of females impregnated per month by sialoadenectomized, ( $Z$ ) sham-operated and $(\square)$ intact ICR male mice. Males were caged individually with females for a maximum pairing period of 6 days. Five males were used in each group, therefore, maximum possible number of pregnant females is 20 .

reproductive performance between sialoadenectomized and sham-operated DDY mice after cohabitation for 36-48 h. Our results on the reproductive performance of sialoadenectomized mice observed for 14 weeks showed significantly lower fertility rates when compared with sham-operated and intact males, indicating a long-term effect of sialoadenectomy. However, it is possible that the difference between our results and the other reports may be due to the difference in mouse strains used.

Salivary EGF directly stimulates spermatogonial proliferation (spermatocytogenesis) and its production by the submandibular gland is under the influence of testosterone, while secretion of EGF is under the control of the sympathetic nervous system (Byyny et al., 1974). However, the removal of the submandibular gland does not result in complete cessation of spermatogonial cell proliferation. Possible explanations for this could be: (1) EGF may be produced by other organs (Byyny et al., 1972). This was confirmed in the study of Tokida et al. (1988), in which sialoadenectomy performed in DDY mice resulted in lower concentrations but not total loss of EGF; (2) other growth factors of testicular origin affect mitotic activity in the seminiferous tubules (Bellve and Zheng, 1989); and (3) substances like activin and inhibin participate in the control of spermatogenesis (Mather et al., 1990; Van Dissel-Emiliani et al., 1989).

\section{References}

Barka T (1980) Biologically active polypeptide in submandibular glands Journal of Histochemistry and Cytochemistry 28 836-859

Bartlett JMS, Spiteri-Grech J and Nieschlag E (1990) Regulation of insulin-like growth factor I and stage-specific levels of epidermal growth factor in stage synchronized rat testes Endocrinology 127 747-758

Bellve AR and Zheng W (1989) Growth factors as autocrine and paracrine modulators of male gonadal functions Journal of Reproduction and Fertility $\mathbf{8 5}$ 771-793

Byyny RL, Orth DN and Cohen S (1972) Radioimmunoassay of epidermal growth factor Endocrinology 90 1261-1266

Byyny RL, Orth DN, Cohen S and Doyne ES (1974) Epidermal growth factor: effects of androgens and androgenic agents Endocrinology 95 776-782

Carballada R and Esponda P (1992) Role of fluid from seminal vesicles and coagulating glands in sperm transport into the uterus and fertility in rats Journal of Reproduction and Fertility 95 639-648

Clermont Y and Trott M (1969) Duration of the cycle of the seminiferous epithelium in the mouse and hamster determined by means of $3 \mathrm{H}$-thymidine and radioautography Fertility and Sterility 20 805-817

Fisher DA and Lakshmanan J (1990) Metabolism and effects of epidermal growth factor and related growth factors in mammals Endocrine Reviews 11 $418-442$

Furuya S, Endo Y, Oba M, Suzuki S and Nozawa S (1993) Effect of epidermal growth factor on human sperm capacitation Fertility and Sterility $60905-910$

Gosden RG, Richardson DW, Brown N and Davidson DW (1982) Structure and gametogenic potential of seminiferous tubules in ageing mice Journal of Reproduction and Fertility 64 127-133

Gupta C and Jaumotte J (1993) Epidermal growth factor binding in the developing male reproductive duct and its regulation by testosterone Endocrinology 133 1778-1782

Gupta C, Siegel S and Ellis D (1991) The role of EGF in testosterone-induced reproductive tract differentiation Developmental Biology 146 106-116

Haneji T, Koide SS, Tajima $Y$ and Nishimune $Y$ (1991) Differential effects of epidermal growth factor on the differentiation of type A spermatogonia in adult mouse cryptorchid testes in vitro Journal of Endocrinology 128 383 -388

Ikeda H, Mitsuhashi T, Kubota K, Kuzuya N and Uchimura H (1984) Epidermal growth factor stimulates growth hormone secretion from superfused rat adenohypophyseal fragments Endocrinology 115 556-558

Mather JP, Attie KM, Woodruff TK, Rice GC and Phillips DM (1990) Activin stimulates spermatogonial proliferation in germ-Sertoli cell cocultures from immature rat testis Endocrinology 127 3206-3214

Noguchi S, Ohba Y and Oka T (1990) Involvement of epidermal growth factor deficiency in pathogenesis of oligozoospermia in streptozotocin-induced diabetic mice Endocrinology 127 2136-2140 
Peerheentupa J, Lakshmanan J, Hoath SB and Fisher DA (1984) Hormonal modulation of mouse plasma concentration of epidermal growth factor Acta Endocrinologica 107 571-576

Radhakrishnan B and Suarez-Quian CA (1992) Characterization of epidermal growth factor receptor in testis, epididymis and vas deferens on non-human primates Journal of Reproduction and Fertility 96 13-23

Russell LD, Weiss T, Goh JC and CurI JL (1990) The effect of submandibular gland removal on testicular and epididymal parameters Tissue and Cell $\mathbf{2 2}$ 263-268

Skakkebaek NE and Heller CG (1973) Quantification of human seminiferous epithelium journal of Reproduction and Fertility 32 379-389

Sordoillet C, Chauvin MA, de Peretti E, Morera AM and Benahmed M (1991) Epidermal growth factor directly stimulates steroidogenesis in primary cultures of porcine Leydig cells: action and site of actions Endocrinology $\mathbf{1 2 8}$ $2160-2168$

Suarez-Quian CA and Niklinski W (1990) Immunocytochemical localization of the epidermal growth factor receptor in mouse testis Biology of Reproduction 43 1087-1097

Suarez-Quian CA, Oke BO and Radhakrishnan B (1994) Relationship between submandibular gland epidermal growth factor and spermatogenesis in $\mathrm{C} 3 \mathrm{H}$ mice Tissue and Cell 26 285-298
Tajima Y, Sakamaki K, Watanabe D, Koshimizu U, Matsuzawa T and Nishimune Y (1991) Steel-Dickie $\left(\mathrm{Sl}^{\mathrm{d}}\right)$ mutation affects both maintenance and differentiation of testicular germ cells in mice Journal of Reproduction and Fertility $\mathbf{9 1}$ $441-449$

Taylor GT, Weiss J, Frechmann T and Haller J (1985) Copulation induces an acute increase in epididymal sperm number in rats Journal of Reproduction and Fertility $73 \quad 323-327$

Tokida N, Shinoda I, Kurobe M, Tatemoto Y, Mori M and Hayashi K (1988) Effect of sialoadenectomy on the level of circulating mouse epidermal growth factor (mEGF) and on the reproductive function of male mice Journal of Clinical Biochemistry and Nutrition 5 221-229

Traish AM and Wotiz HH (1987) Prostatic epidermal growth factor receptor and their regulation by androgens Endocrinology 121 1461-1467

- Tsutsumi O, Kurachi H and Oka T (1986) A physiological role of epidermal growth factor in male reproductive function Science $233975-977$

Van Dissel-Emiliani FMF, Grootenhuis AJ, de Jong FH and de Rooij DG (1989) Inhibin reduces spermatogonial number in testes of adult mice and chinese hamsters Endocrinology 125 1898-1903

Verhoeven G and Cailleau J (1986) Stimulatory effects of epidermal growth factors on steroidogenesis in Leydig cells Molecular and Cellular Endocrinology 47 99-106 